\title{
Large nesting birds threaten arboretum trees
}

With thousands of nesting egrets and herons threatening the health of trees in the UC Davis Arboretum's Shields Oak Grove, wild-bird experts are testing unusual but humane means to discourage the birds.

The Shields Oak Grove has been in existence since 1963 but big, colonial wading birds did not begin nesting there until 2000. The rookery quickly grew to one of the largest nesting colonies in Yolo County. Last year, more than 2,400 egrets and herons nested or roosted there, producing more than 850 chicks.

During nesting season, the grove is permeated with the smell of excrement, or guano, of four bird species: cattle egrets, black-crowned night herons, great egrets and snowy egrets. The guano of thousands of those birds coats the oak trees' branches, twigs and leaves like white paint. The ammonia in the guano is enough to kill some leaves outright. Others die because they are deprived of the sunlight needed for photosynthesis.

Furthermore, rainfall and irrigation leach guano salts into the soil, where they are taken up by the roots and carried through the tree's circulatory system to all the leaves.

As the number of birds grows, so does the number of trees being affected, says Ellen Zagory, director of horticulture for the UC Davis Arboretum.

"Ammonia is toxic and causes defoliation. Guano is opaque, so it blocks photosynthesis and causes defoliation. Salts stunt the growth of roots and shoots, and cause margin burn on the leaves and defoliation," Zagory says. "Complete defoliation of a branch over several years means that branch dies." Ultimately, dead branches can lead to weak and dying trees.

\section{Balancing trees and birds}

In hopes of finding a sustainable balance for both trees and birds, the arboretum's oak and wildlife management team began field-testing two nesting deterrents in early March. First, arboretum staff removed all remnants of last year's nests from a group of 15 oak trees. Mana Hattori, a researcher at the UC Davis Museum of Wildlife and Fish Biology, will compare subsequent nesting activity in those 15 trees with activity in 15 similar control trees that were left alone.

Beginning next week, in a different part of the grove, Hattori will test another method that has been successful with nuisance colonies elsewhere in the United States: She will shine a laser light at

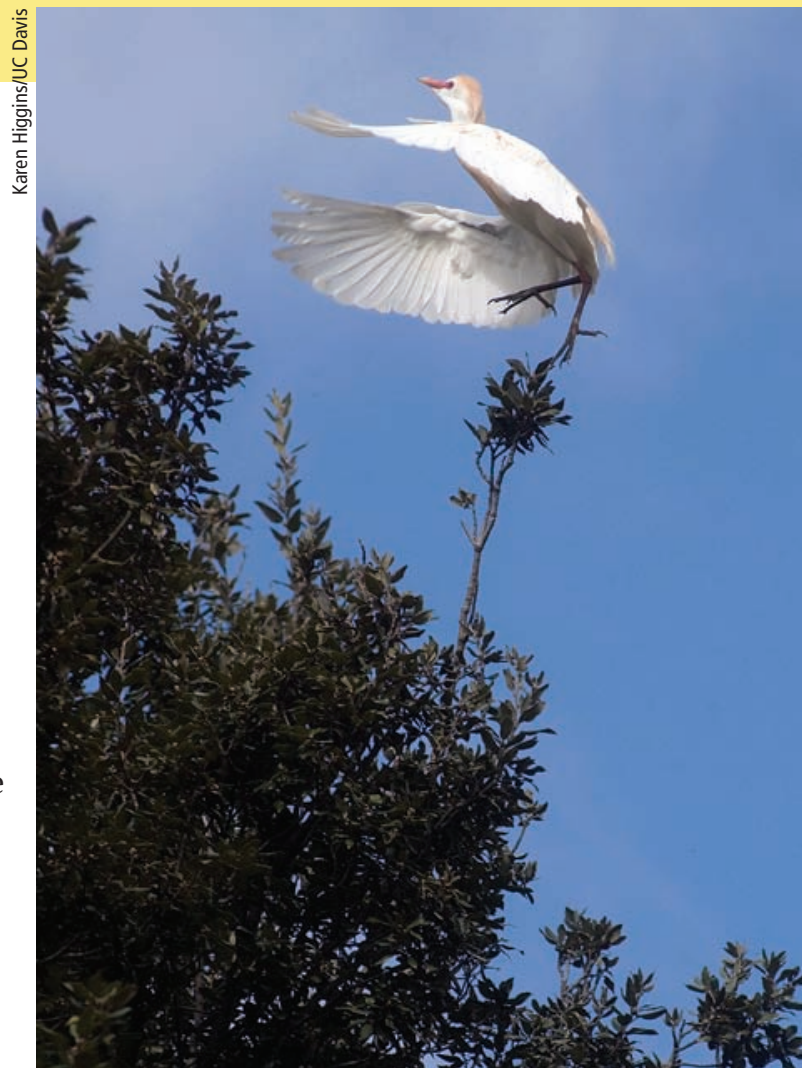

cattle egrets when they land in the trees.

Andy Engilis, museum curator and a wild-bird expert on the team, says the light is not harmful to the egrets: "It basically spooks them and they fly off." The laser will be aimed at only cattle egrets that have not begun nesting. It will not be used on the other species of birds, which already have eggs and chicks.

"If this works, it gives us a method we can use in the future," Engilis says. "We are trying to protect a bird resource that has state value and a grove of trees that is very important, and we're trying to find an equilibrium that will work with both groups."

\section{Valuable resources}

The Shields Oak Grove contains the largest collection of mature oaks in the southwestern United States - 304 trees representing 87 types of oak species, varieties and hybrids, some of which are rare and endangered. It is a partner in the national oak collection of the North American Plant Collections Consortium.

Herons and egrets are similarly valued resources. In 2006 and 2007, the team's gentle nesting disincentives included the structural pruning of trees; removing some redundant and crowding trees; removing the remnants of the previous years' nests; and tying shiny Mylar streamers and balloons to the treetops. The number of nests built by three of the four species - the blackcrowned night herons, great egrets and snowy egrets - leveled out at about 320 .

But the fourth species, the cattle egret, increased its nests from 21 in 2005 to 495 in 2007. Not native Californians, cattle egrets originated in Africa, traveled to South America and became established in the 1930s, then rapidly spread north, reaching Northern California by the mid-1990s.

"In other parts of California, such as the Salton Sea, cattle egrets have swamped out other nesting species," Engelis says. "They nest in very dense colonies. When they find a good area, they will come in big numbers, even to the detriment of other species."
Large wading birds, including the great egret, began nesting in the Shields Oak Grove at UC Davis in 2000. The rookery now contains thousands of birds, which threaten hundreds of mature oaks in the grove. 